\title{
POESÍA Y TRADUCCIÓN EN EL EXILIO: LA OBRA DE ALAÍDE FOPPA
}

\author{
An Van Hecke \\ Katholieke Universiteit Leuven. Facultad de Letras, Leuven, Bélgica.
}

\begin{abstract}
Resumen: Este artículo analiza la poética de traducción de la autora guatemalteca Alaíde Foppa (1914) y el contexto en el que tradujo como exiliada en México. En 1980 fue secuestrada en Guatemala y hasta ahora se desconoce el paradero de sus restos. Foppa era una mujer polifacética: poetisa, activista, feminista, crítica de arte, editora, académica y traductora. El análisis se centra en tres traducciones, del francés, del italiano y del inglés: la poesía de Paul Éluard, Miguel Ángel y Mary Oxlie de Morpet. También se examinan los paratextos como prólogos y ensayos con el fin de entender la visión de Foppa sobre la traducción de poesía y sus estrategias de traducción. El análisis apunta hacia una tendencia a la "traducción recreativa" (Jones 2011) y la "traducción como obra personal" (Campos 1996). Al mismo tiempo se investiga hasta qué punto su exilio y su multilingüismo tuvieron un impacto sobre su trabajo como traductora.
\end{abstract}

Palabras clave: Alaíde Foppa. Guatemala. México. Exilio. Traducción de poesía.

\section{POETRY AND TRANSLATION IN EXILE: ALAÍDE FOPPA'S OEUVRE}

\begin{abstract}
This article analyzes the translation poetics and the translation context of Guatemalan author Alaíde Foppa (1914) who lived in exile in Mexico. In 1980 she was kidnapped in Guatemala and the resting place of her remains is still unknown. Foppa was a woman of many talents: she was a poet, activist, feminist, art critic, editor, academic and translator. The focus is on three of the available poetry translations, from French, Italian and English: Paul Éluard, Michelangelo and Mary Oxlie of Morpet. The analysis of paratexts such as prologues and essays will help
\end{abstract}


reveal Foppa's vision on poetry translation and translation strategies. The analysis shows a tendency towards "recreative translation" (Jones 2011) and "translation as a personal oeuvre" (Campos 1996). At the same time, the paper aims at exploring to what extent Foppa's situation as an exile as well as her multilingualism had an impact on her work as a translator. Keywords: Alaíde Foppa. Guatemala. Mexico. Exile. Poetry translation.

\section{Desplazamientos y exilio}

En su libro After Exile Amy Kaminsky escribe: “The prediscursive sense of rootedness [...] and the trauma of displacement, followed by learning the new space, find their counterparts in the representation of fictional or poetic space, wherein language provides the means to establish as well as to recover a sense of place" (Kaminsky 58). Esta "recuperación de un sentido de lugar" se manifiesta claramente en el caso de Alaíde Foppa, poetisa y traductora guatemalteca que vivió exiliada en México. Foppa nació en Barcelona en 1914, de padre italo-argentino y de madre guatemalteca. Su padre era corresponsal de guerra para La Nación de Buenos Aires y posteriormente ejerció un cargo diplomático en Europa. Foppa vivió en Bruselas, donde cursó estudios secundarios y siguió clases de danza clásica en la escuela del Ballet real (Rossi 105). Cursó su educación superior en Italia, donde se especializó en literatura italiana y hablaba perfectamente francés. En los años cuarenta decidió trasladarse a Guatemala, donde llegó en un momento difícil de protestas contra la dictadura de Jorge Ubico. Junto con su marido Alfonso Solórzano salió rumbo al exilio a México, país donde crecieron sus cinco hijos. Según Franca Bizzoni, Foppa no sabía a ciencia cierta lo que era: "Ella se sentía muy ligada a Italia, no sé si italiana, mexicana o guatemalteca, ella ya no sabía ni lo que era. $¡ O$ argentina! No tenía una nacionalidad definida, digamos, lo que sí se sentía era guatemalteca e italiana y amaba mucho este país." (Bizzoni en Salinas 83). También la cuestión de la lengua materna es complicada aunque bien se puede considerar a Foppa como una 
persona perfectamente bilingüe (español e italiano), lo que se desprende del hecho de que escribiera sus primeros poemas en italiano (Foppa en Lorenzano s.p.).

El 19 de diciembre de 1980, cuando Alaíde Foppa estaba de visita en casa de su madre en Guatemala, fue secuestrada. Era la época del dictador Romeo Lucas García y hasta ahora se desconoce con seguridad el paradero de sus restos. Desde entonces ya se le han dedicado varios homenajes que se han centrado principalmente en el contexto político. El objetivo de muchos de estos textos consiste en llamar la atención sobre el drama y mantener vivo su nombre. Durante los primeros años después del secuestro, varios amigos esperaban o reclamaban todavía que fuera devuelta viva (Paniagua 22). También Augusto Monterroso trató de dar un lugar a este duelo. En su diario La letra e, de 1984, observa desde el avión su patria Guatemala, rumbo a Managua, y recuerda con dolor a su amiga:

Guatemala "pasa" ahora debajo de nosotros. Lo imagino [...]. Abajo, en las montañas, en las ciudades y en las aldeas, nuestros amigos en lucha, nuestros muertos; un día más en sus vidas y en sus muertes por una causa que tampoco es la de los norteamericanos, y eso dice suficientemente qué causa es ésa: la causa popular, la de la poeta Alaíde Foppa, torturada, muerta y desaparecida; la de sus hijos, muertos en combate. (Monterroso 154)

Asimismo, a Elena Poniatowska, aún en 2012, le cuesta aceptar su desaparición definitiva y piensa: "Ahorita va a abrir la puerta y va a entrar. Sonará el teléfono y oiré su voz." (Poniatowska s.p.). Muchos autores que la conocieron personalmente destacan su carácter dulce, su personalidad encantadora, su cultura y también subrayan su trabajo como feminista e intelectual. Al principio su compromiso político en el exilio no era muy pronunciado. La familia Solórzano-Foppa se había exiliado más por el esposo Alfonso, que era comunista. Es más, según Rossi, Foppa "nunca se 
sintió exiliada. Se identificó plenamente con el ambiente humano e intelectual que encontró" (Rossi 106). Su casa se convirtió en un lugar de encuentro de intelectuales. La vida en México era para Alaíde Foppa sin duda un enriquecimiento a nivel profesional, una promesa, tal como lo define Amy Kaminsky:

\begin{abstract}
The exile's sense of identity and sense that exile is a u-topia (a no-place) with promise - the promise that one will survive at least - transform into the diasporan subject's sense of being elsewhere, some place, if not the place. Diaspora connects the exiles with intellectuals and writers who were already outside the country when the coups happened, who also feel connected. (Kaminsky 17-18)
\end{abstract}

Foppa empezó a comprometerse sobre todo después de la muerte de su hijo, Juan Pablo, que había participado en la guerrilla guatemalteca. Su lucha por los derechos de la mujer y de los indígenas ha sido fundamental para el feminismo en México (Ludec 117) donde fue cofundadora de la revista Fem en 1976. Su trágica muerte es también el tema central del libro de Gilda Salinas, Alaíde Foppa. El eco de tu nombre (2002), que combina testimonios de amigos y familiares con fragmentos ficticios en los que la autora trata de imaginarse lo que debe de haber pasado por la mente de Foppa en los últimos momentos de su vida.

En 2014, en el centenario del nacimiento de la poetisa, se estrenó el documental Alaíde Foppa, la sin ventura. Con ocasión de la entrega del premio al mejor documental internacional en el Festival Ícaro, la hija, Silvia Solórzano, dijo que "en contraste con años anteriores, en que la familia solía conmemorar el aniversario luctuoso, ahora decidieron que el centenario merecía una celebración" (Solórzano citada en MacMasters, s.p.). Uno de los primeros pasos en la revaloración de su obra poética de hecho fue la publicación de la Antología poética, elaborada por Luz Méndez (2000). 


\section{Alaíde Foppa, traductora}

Alaíde Foppa es conocida sobre todo por su poesía, pero era una mujer polifacética: activista, crítica de arte, editora de la revista Fem, académica en la UNAM donde impartía clase de literatura italiana y estudios de la mujer y, finalmente, traductora. En muchos textos sobre Foppa, al enumerar estas actividades, su trabajo como traductora suele añadirse al final, como si fuera algo secundario e insignificante respecto a sus otras actividades. Incluso ciertos autores ni siquiera mencionan la labor de traductora de Foppa (Salinas 130). Sin embargo, su trabajo en la traducción no debe entenderse como un aspecto secundario de su obra, sino fundamental.

Foppa tradujo textos de índole muy diversa, generalmente por encargo, y la traducción formaba parte de sus ingresos. Ya a principios de los años 40, cuando se acababa de instalar en Guatemala, trabajó como traductora en la Embajada de Italia y colaboró como crítica de arte y poetisa en el grupo Saker-Ti. ${ }^{1}$ En esta misma época fue directora del Instituto Italiano de Cultura (Salinas 51) y lo más probable es que su trabajo de traductora estuviera ligado a esta dirección del Instituto. Tal como sugiere Salinas, buscaba y aceptaba estos trabajos porque le gustaba la independencia económica y así no dependía de su marido ni de su madre (Salinas 51). También en México se dedicó a la traducción y la interpretación: “cada vez tenía más trabajo como traductora simultánea: del italiano al francés y viceversa, del italiano y del francés al español o a la inversa, además de la posibilidad de traducirlos al español de España, de México, de Guatemala o de la Argentina, que es el mismo pero no es igual" (Salinas 93). Foppa tenía pues grandes aptitudes como traductora e intérprete de diferentes idiomas, en las dos direcciones.

Para Foppa, que se integró rápidamente en la vida cultural mexicana, la traducción siempre formó parte de sus actividades: "Y

\footnotetext{
${ }^{1}$ Gracias a su colaboración con el grupo Saker-Ti en Guatemala, Foppa conoció a Carlos Illescas, Augusto Monterroso y otros intelectuales de la llamada generación del 40. (Salinas 48)
} 
no es que fuera una mujer rica, vivía de sus clases en la UNAM, de sus traducciones y artículos en los diarios. Más que a las cosas, Alaíde amaba el arte, amaba la vida..." (Lugo citada en Salinas 107). Foppa también amaba profundamente las lenguas -el español, el italiano y el francés- ${ }^{2}$ y su fascinación por las palabras se revela en su propia poesía, como se observa en los primeros versos de un poema dedicado a José Luis Cuevas, pintor, grabador y escultor mexicano nacido en 1931 en la Ciudad de México:

\author{
Querido José Luis \\ Dichoso tú que no necesitas palabras \\ Yo lucho con ellas todos los días, \\ Las persigo, las rechazo \\ se me escapan, \\ y si logro atrapar alguna, \\ no, no era ella, \\ o me deja apenas un polvillo de oro \\ entre los dedos.
}

(Foppa citada en Salinas 132)

El artista plástico trabaja con imágenes y no necesita palabras, a diferencia del poeta que sí las necesita. Es una lucha diaria, porque paradójicamente, aunque las necesita no logra atraparlas. El artista plástico y el poeta trabajan con herramientas distintas, pero se entienden ya que comparten los mismos espacios artísticos e intelectuales. En 1975 Foppa publicó una obra titulada Confesiones de José Luis Cuevas, un reflejo de las conversaciones entre ambos.

\footnotetext{
${ }^{2} \mathrm{Su}$ fascinación por las lenguas explica también su obsesión por escribir sin faltas, como recuerda su hija Laura: "Mi mamá tenía una gran preocupación por el bajo nivel académico de América Latina, para ella era terrible que los muchachos de la universidad escribieran con faltas de ortografía, de sintaxis, con exceso de gerundios." (Solórzano citada en Salinas 120-121)
} 


\title{
3. La traducción de poesía
}

La traducción de poesía es probablemente uno de los campos de la traducción más polémicos. El concepto de intraducibilidad de la poesía, que ha contado con muchos defensores, cuestiona la posibilidad de que se puedan realizar este tipo de traducciones (Íñiguez Rodríguez 201). En su libro From World to World Cees Koster parte de la doble condición de la traducción en general: por un lado, como texto independiente, una vez producido funciona en su entorno cultural como cualquier otro texto; por otro lado, adquiere la cualidad de texto derivado, ya que se trata de una representación, una reconstrucción o reproducción de otro texto (Koster 16). Koster desarrolla más esta división:

\begin{abstract}
Translation as a specific form of interpretation, it seems justified to say at this point, always involves recontextualization. Retrospectively, in its status as reproduction it may be considered to constitute an act of recontextualization, and in its status as independent text it is itself subject to the entire mechanism of de-and recontextualization. (Koster 59)
\end{abstract}

Koster se centra entonces en la manera en que se realizan los cambios o shifts en este acto de recontextualización. Quizá más que en otras traducciones, en la traducción poética, se manifiesta una pérdida inevitable del texto fuente, tal como lo explica Venuti:

The poem that is the object of translation inevitably vanishes during the translation process, replaced by a network of signification - intertextual, interdiscursive, intersemiotic that is rooted mainly in the receiving situation. Hence poetry translation tends to release language from the narrowly defined communicative function that most translations are assumed to serve, whether the genre of their source 
texts is technical, pragmatic, or humanistic - namely, the communication of a formal or semantic invariant contained in the source text. (Venuti 128)

Para este estudio sobre Foppa ha resultado muy útil el modelo del poeta y crítico mexicano Marco Antonio Campos, quien, en su artículo "Poesía y traducción" (1996), aborda hasta siete formas distintas de asumir la traducción de poesía: la traducción como creación, la traducción literal, la traducción libre, la traducción como obra personal, la traducción desde una estructura plurilingüe, la traducción como adaptación moderna de un texto antiguo y la adaptación. Francis R. Jones, en un artículo más reciente, titulado "Poetry Translation" (2011), reduce los diferentes tipos a tres categorías:

1. 'Literals' or 'prose renderings' recreate source semantics but delete source poetic features.

2. 'Adaptations', 'versions' or 'imitations' change or abandon key aspects of source-poem semantics, and sometimes its poetic features, for the sake of target-poem effectiveness.

3. 'Recreative translations' try to recreate a source poem's semantic and poetic features in a viable receptor-language poem. (Jones 2)

El siguiente análisis se centra en tres traducciones disponibles de Alaíde Foppa, de tres idiomas diferentes: el francés, el italiano y el inglés. Son traducciones de Paul Éluard, Miguel Ángel Buonarroti y Mary Oxlie de Morpet, una poetisa inglesa poco conocida del siglo XVII. ${ }^{3}$ Foppa no tradujo estos textos poéticos por

3 Resultó muy difícil encontrar traducciones realizadas por Foppa. Hice investigaciones en México, en la UNAM y en librerías, pero aparentemente gran parte de su obra ha caído en el olvido. Encontré El ave Fénix y La poesía de Miguel Ángel en ediciones de segunda mano. Para los textos de la revista Fem en el Centro de Estudios Mexicanos de la Universidad de Amberes (Bélgica) pude contar con la ayuda de la bibliotecaria Verónica Méndez. Estas búsquedas llevaron al descubrimiento de estas tres traducciones únicamente. 
encargo, sino por iniciativa propia. Lo vio como sus "proyectos" personales (Salinas 80). Es lo que Jones sugiere en su descripción de las actividades de un traductor de poesía:

Poetry translators are often also involved in wider textproduction processes: choosing poems for a selection of a source poet's work, for instance; writing a critical commentary about the source poet, poems and cultural background, and often explaining their own translation approach; or giving public readings with the source poet. (Jones 5)

La obra de Alaíde Foppa como traductora coincide con esta descripción. Foppa realizó la selección de estos tres poetas, pero además, en los casos de Éluard y Miguel Ángel, escribió comentarios críticos y aclaraciones sobre el proceso de traducción. Para Miguel Ángel lo hace aparte en una "Nota a la traducción" (Foppa, La poesía de Miguel Ángel 27). Las tres traducciones hechas por Foppa se estudiarán por orden cronológico de publicación. Estos tres poemas sirven de ilustración de ciertas tendencias en la visión que Foppa tenía sobre la traducción de poesía. Asimismo, los prólogos y los ensayos en los que Foppa explica sus estrategias de traducción dan una mejor idea del contexto en el que se publicaron estas traducciones.

La traducción del último libro de Paul Éluard (1895-1952), El ave Fénix, realizada en colaboración con la viuda del poeta, Dominique Éluard, fue publicada en 1961. Juntas hicieron una selección del libro Le Phénix (1951). Foppa apreció mucho la colaboración de Dominique, tal como explica en el prólogo: “Colaboradora incomparable en la traducción, Dominique Éluard ha podido aclarar dudas cada vez que el texto presentaba alguna ambigüedad" (Foppa en Éluard 11). Llama la atención que Foppa, activista de izquierda, enfoca en su texto la aparente paradoja entre la expresión poética y la militancia política del autor. Éluard es conocido por su compromiso con la causa del comunismo soviético, pero en su poesía aparecen otros "impulsos" según Foppa. La poeta trata de reconciliar ambos aspectos: 
El hecho es que él no se dividió nunca en dos, y si una parte de su personalidad encontró expresión en la poesía y otra en la lucha política, el impulso interior que animaba sus dos maneras de ser era el mismo, o, dicho de otra manera, la inspiración de su poesía y la razón de su militancia, las encontraba en un solo lugar [...], porque ambas nacían del más hondo impulso que mueve a los hombres: el amor. (9-10)

Foppa analiza también el estilo de Éluard y establece una distinción entre los poemas: muchos son "absolutamente límpidos", pero otros son difíciles y "herméticos por excesiva síntesis". Falta a veces "el eslabón lógico entre las palabras" (11). Por lo general Éluard utiliza el verso libre sin puntuación. ¿Qué posición adoptará entonces la traductora? Esta es la respuesta de Foppa:

En la traducción, hemos conservado las mismas características formales, tratando de salvar, en el mayor grado posible, los valores poéticos. Espero que esta fidelidad, mantenida a veces difícilmente, logre transmitir al lector de lengua española, lo esencial de esta poesía. (11)

Su prioridad consiste pues en tratar de recrear las características poéticas formales, pero al mismo tiempo espera que al ser "fiel" a estos valores poéticos formales, logre transmitir "lo esencial de esta poesía", es decir, la misma semántica también. Lo que Foppa se propone en el prólogo se confirma cuando se cotejan los poemas originales con las traducciones, como en la primera estrofa de Chanson (Le Phénix 49) / Canción (El ave Fénix 49): 
Chanson

Paul Éluard

Dans l'amour la vie a encore L'eau pure de ses yeux d'enfant Sa bouche est encore une fleur Qui s'ouvre sans savoir comment
Canción

Paul Éluard

En el amor la vida aún tiene El agua pura de sus ojos niños Su boca es todavía una flor Que se abre sin saber cómo

Es un poema de tres estrofas con verso libre, con solo un punto al final del poema. En la traducción Foppa recrea la misma forma poética, aunque la rima desaparece en la traducción. A nivel semántico se queda muy cerca de la versión original. Foppa se situaría en lo que Jones llama el tercer tipo de traducción de poesía, la "traducción recreativa" (Jones 2).

La poesía de Miguel Ángel, traducida por Alaíde Foppa, salió a la luz en 1966. Salinas llama esta traducción "un proyecto personal y loco" de una "defensora de injusticias" (Salinas 80 ) porque recupera la poesía de Miguel Ángel Buonarroti, un aspecto del gran artista que durante mucho tiempo fue ignorado. A diferencia de la traducción de la poesía de Paul Éluard, que solo incluye la versión española, esta edición de Miguel Ángel es bilingüe. La traducción aparece debajo del poema original. Las ediciones bilingües son muy apreciadas por los aficionados de la poesía, como apunta Marco Antonio Campos, a quien le "resulta difícil y aun enfadoso leer los libros que solo contienen el poema traducido". Añade Campos: "las ediciones bilingües tienen la ventaja que, si se conoce la lengua fuente, podemos hacer al menos tres lecturas: la de la versión original, la versión traducida y la lectura comparativa" (Campos 60). En este libro de Miguel Ángel, Foppa incluye al inicio un ensayo, "La poesía de Miguel Ángel”, en el que analiza ampliamente la vida y la obra del artista italiano y compara su trabajo como pintor, escultor y arquitecto con su poesía: 
Es posible que la poesía fuera postergada en el elogio y casi dejada a un lado, porque no correspondía a la imagen de creador poderoso que evoca su arte, ya que la poesía de Miguel Ángel expresa casi lo contrario: la debilidad del hombre, su impotencia, su desdicha, su esclavitud. (Foppa, La poesía de Miguel Ángel 9)

Aunque el gran pintor y escultor renacentista no suele ser recordado por su poesía, su producción fue considerable. El profesor italiano Giardi recopiló trescientas dos composiciones en total de las que Foppa tradujo treinta (Foppa, La poesía de Miguel Ángel, 27). La traducción es aquí una manera de recuperar esta poesía olvidada. El proyecto era difícil y le tomó muchos años a Foppa, primero porque traducir a Miguel Ángel "no era tarea sencilla ni expedita", y en segundo lugar, porque no era evidente encontrar editor o recursos (Salinas 83). Solo después de varios años, en 1966, logró publicar el poemario. En el ensayo introductorio Foppa aclara dónde se sitúa la dificultad de traducir la poesía de Miguel Ángel:

\begin{abstract}
Sus ásperas y difíciles rimas hacen casi imposible una traducción en verso, pero bastan algunos fragmentos, en traducción literal, para dar una idea de lo que puede ser en Miguel Ángel un desahogo cargado de expresiones prosaicas, en violento contraste con el alto vuelo que en otros momentos alcanza su fantasía. El poema se inicia con el tema de la cárcel, asociado esta vez a un concepto mágico, seguramente familiar a sus contemporáneos. (Foppa, $L a$ poesía de Miguel Ángel 21)
\end{abstract}

Es importante esta aclaración sobre las rimas "ásperas y difíciles" de Miguel Ángel, algo que Foppa ilustra con una traducción de algunos poemas breves que ella denomina "literal", con el único objetivo de informar al lector sobre el contenido de estos versos. En cambio, para la traducción de los poemas seleccionados más adelante, Foppa optó por una traducción que pretende ser “poé- 
tica" y no literal. Así lo explica en la "Nota a la traducción" que sigue al ensayo sobre la vida y la obra de Miguel Ángel. Tal como hizo para la traducción de Éluard, Foppa quiere "salvar" el valor poético. Aquí también se trataría de una traducción recreativa con atención tanto hacia la semántica como hacia las características poéticas. Para Foppa resulta fundamental la forma poética:

\begin{abstract}
En la traducción de los sonetos y de la mayoría de las otras composiciones está observada la rima consonante. En otros poemas de corte más libre (fragmentos, esbozos, o sonetos inconclusos), he cambiado a veces consonantes por asonantes sin alterar la medida del verso y, muy poco, los acentos. El verso de Miguel Angel es el endecasílabo, al que se alterna en los madrigales el heptasílabo. (Foppa, $L a$ poesía de Miguel Angel 28)
\end{abstract}

Foppa añade que al privilegiar la forma poética su preocupación es que "esper[a] no haber traicionado el sentido de lo que Miguel Ángel quiso decir, y sobre todo, su sentimiento" (Foppa, La poesía de Miguel Angel 28). Además del dilema entre forma y significado, el uso de la palabra "traicionar" revela el bien conocido miedo de ser "traidora" en lugar de "traductora". Veamos cómo consigue Foppa los objetivos que se propone en uno de los poemas más conocidos del autor (La poesía de Miguel Angel 48). De las cuatro estrofas se cita aquí solo la primera:

Non ha l'ottimo artista alcun

concetto

ch 'un marmo solo in se non circonscriva

col suo soverchio, e solo a quello arriva

la man che ubbidisce all'intelletto.
No tiene el gran artista algún concepto

que no esté en el mármol contenido con exceso, mas solo lo ha obtenido la mano que obedece al intelecto. 
Foppa recrea en español una estructura con rimas que se asemeja a la del poema original en italiano. Al comparar estos poemas con la traducción de Éluard, resulta que Foppa se ha impuesto un reto aún más ambicioso. Por otra parte, lo que convierte esta edición de Miguel Ángel en un libro aún más interesante, es la inclusión de un poema de la misma Foppa, "A Miguel Ángel. En el IV centenario de su muerte" (67-69). Aquí se manifiesta la estrecha relación entre la poesía de Foppa y sus traducciones. Al hacer esto Foppa se sitúa en lo que Campos llama "la traducción como obra personal”, ya que hay una incorporación de la obra traducida en la propia obra. Afirma Campos: "es tanta la afinidad que siente el autor con los poemas traducidos, que ya acaban siendo parte de su sensibilidad, de su imaginación, de su recuerdo, de su misma sangre" (Campos 57). Traducir a Miguel Ángel y hacer poemas sobre él es una manera de "dialogar" con el poeta italiano de la misma manera que ha observado Tcherepashenets en el caso de Borges: "Translation is an enactment of a dialogue, an imaginary anthropological encounter and a confession" (191).

Según Mario Monteforte Toledo, la poesía de Foppa presenta una clara influencia de la poesía italiana: "[...] ella era de la línea de los esteticistas Montale, Quasimodo, etc.; tiene mucho de italiano en su poesía: un poco seca, elegante, prudente, muy recatada era la poesía de ella" (Monteforte Toledo citado en Salinas 94). El gran interés por la poesía italiana se observa también en un artículo de Fem, titulado "Lo que escriben las mujeres", donde Foppa se refiere a "la severa Vittoria Colonna" quien "no deja de añorar al marqués que la dejó viuda, sorda al platónico amor de Miguel Ángel” (Fem 3, 10, 1979, 5).

La tercera traducción es de un poema de Mary Oxlie de Morpet, publicado en la revista Fem (3, 10, 1979: 62) sin título, aunque en la parte de arriba aparece una frase que funciona como tal: "En el siglo de Shakespeare una mujer se dirige a un poeta amigo". Este título es más bien una explicación, probablemente de la mano de Foppa. La "mujer" es Mary Oxlie de Morpet y el destinatario William Drummond de Hawthornden (1585-1649), un poeta escocés. De hecho, según el Oxford Dictionary of National Biography, Mary Oxlie es 
conocida solo por este poema y de su vida no se sabe casi nada. Este poema de 52 líneas en total es "una apología sorprendente de la creatividad femenina" (Oxford Dictionary, traducción propia). Debajo de la traducción en Fem se encuentra la siguiente referencia: "Citado por Tillie Oslen en Silences. Traducción A.F." Solo se han publicado las tres primeras estrofas, en total diez versos, pero dan ya una idea del contenido del poema en su totalidad. Como en Fem no se recoge el texto original, se incluyen aquí las dos versiones:

I never rested on the Muses bed, Nor dipt my quill in the Thessalian fountaine, My rustick Muse was rudely fostered,

And flies too low to reach the double mountaine.

Then do not sparkes with your bright Suns compare, Perfection in a Womans work is rare;

From an untroubled mind should verses flow;

My discontents make mine too muddy show;

And hoarse encumbrances of houshold care;

Where these remaine, the Muses ne'er repaire.

(Oxlie 5-6)
Nunca en el lecho de las Musas descansé

Ni mojé mi pluma en la fuente Tesalia,

Fue mi rústica Musa rudamente nutrida

Y vuela muy bajo, para alcanzar la alta montaña.

No compares, pues, mis chispazos con tus brillantes Soles, La perfección en obra de mujer es rara.

De mente imperturbada han de fluir los versos.

Turbios nacen los míos por mis descontentos.

Y los sordos estorbos de cuidados caseros

Entre los que se quedan, nunca los remedian las Musas.

(Citado por Tillie Oslen en Silences. Traducción A.F.) (Fem 3, 10 , enero-octubre 1979,62$)$ 
Este poema del principio del siglo XVII mantiene su vigencia en los años setenta del siglo XX. En particular el verso "La perfección en obra de mujer es rara" es significativo. La percepción de la mujer como ser inferior al hombre sigue existiendo en la sociedad latinoamericana y vuelve a aparecer en otros artículos de Foppa. Así, por ejemplo, en el artículo "Lo que dice el diccionario" Foppa sintetiza las definiciones del Diccionario de la Real Academia: "Como se ve, para el Diccionario las mujeres son de dos tipos: domésticas o rameras." (Fem 1978: 52-55). Ambos textos, el poema de Oxlie y el artículo de Foppa, comparten la misma temática de la inferioridad de la mujer, pero se distinguen también. Oxlie parece aceptar esta situación, mientras que en su artículo Foppa la denuncia.

Cabe subrayar la situación de la traducción de este poema de Mary Oxlie en el conjunto de la revista Fem. Márgara Millán, en su estudio sobre políticas de traducción del feminismo mexicano, analiza cómo las revistas feministas son parte de todo un aparato "material-discursivo" que traduce y disemina teorías: "desde esta perspectiva, las revistas feministas son mediadores culturales." (Millán 822). También en Fem se observa esta labor de las periodistas que consultan otras revistas feministas en el mundo entero y traducen artículos. Así, por ejemplo, Foppa publicó un artículo llamativo titulado "La primera publicación feminista de Japón" (Fem 1978: 97). Foppa también se dedicó a la crítica literaria sobre poesía y, en particular, de mujeres. En Fem destaca su artículo "Lo que escriben las mujeres", que es un repaso de varias escritoras a lo largo de la historia. Según Foppa, "lo primero que escribieron las mujeres fueron poemas de amor, y sobre todo poemas de soledad y añoranza" (Fem 1979, 5). Sin embargo, el poema de Mary Oxlie de Morpet no es un poema de amor. Alude a una temática distinta: la posición de la mujer en la poesía y en la sociedad, muy inferior a la del hombre. El poema refleja una clara política de traducción de la revista al seleccionar textos de diferentes idiomas que apoyan la ideología feminista defendida por las colaboradoras. 


\section{Conclusión}

En los paratextos de las traducciones de Éluard y Miguel Ángel, Foppa analiza el estilo de ambos poetas para explicar después las estrategias de traducción que ha adoptado. Lo hace con precaución y con respeto hacia las formas poéticas realizando traducciones que pueden ser definidas como recreativas. En el caso del poema de Mary Oxlie es importante el contexto de la revista feminista en la que fue publicado. Foppa tenía una gran familiaridad tanto con la poesía francesa como con la italiana o inglesa. Era una exiliada guatemalteca en México, pero su mundo era el de la literatura universal. Se aplica aquí la teoría de Kaminsky sobre la coherencia de la identidad del exiliado: "despite geographical transplantation and the trauma of exile, there is a sense in which identity is coherent, able to incorporate the new into the old" (Kaminsky 134). Por otra parte, no hay duda que su exilio y su multilingüismo sí tuvieron un impacto sobre su trabajo como autora y traductora.

Finalmente, es preciso situar las traducciones de poesía extranjera, como la de Éluard, Miguel Ángel y Mary Oxlie, en el conjunto de la obra poética de Foppa. La transferencia hacia el español de la poesía de autores que tanto le influían en su obra era una manera de apropiarse de esta poesía, de hacerla suya, de meterse aún más en la mente del poeta y "dialogar” con él, incluso desde la poesía, como bien se ilustra en el poema dedicado a Miguel Ángel. Annunziata Rossi califica la poesía de Foppa de "intimista, ensimismada, dirigida a su autoconocimiento" (Rossi 105). Estas son también las características de la poesía que ella tradujo. En la obra de Alaíde Foppa, ambas actividades, la traducción y la creación, se sobreponen y confluyen. El diálogo imaginario con los autores de los poemas que traduce, a través de traducciones, ensayos y prólogos, nutre y enriquece el mundo literario de esta fascinante autora guatemalteca. 


\section{Referencias}

Alaíde Foppa, la sin ventura. Documental dirigido y producido por María del Carmen de Lara y Leopoldo Best. 2014. Consultado 27/06/16. https://www. youtube.com/watch? $\mathrm{v}=\mathrm{W} 3 \mathrm{Auu} 2 \mathrm{DPVzY}$.

Campos, M.A. "Poesía y traducción”. Hieronymus Complutensis 3, 1996. Consultado 27/06/16. http://cvc.cervantes.es/lengua/hieronymus/pdf/03/03_051. pdf.

Éluard, Paul. Le Phénix (avec dix-huit dessins de Valentine Hugo). Paris: GLM, 1952.

. El ave Fénix. Poemas. Traducción de Alaíde Foppa y Dominique Éluard, México: UNAM, 1990.

Fem. Nueva cultura feminista, números del 1 al 96, México, 1976-1990.

Foppa, Alaíde. La poesía de Miguel Ángel. Ensayo, traducción y un poema final de Alaíde Foppa. México: Ecuador $\mathrm{O}^{\circ} \mathrm{O}^{\prime} \mathrm{O}$ ', Finisterre, Instituto Italiano de Cultura, 1966.

1976.

. Confesiones de José Luis Cuevas, México, Fondo de Cultura Económica,

. Los dedos de mi mano. Selección de poemas del libro. Asociación de Trabajadores de la Cultura de Guatemala "Alaíde Foppa” 1.3 (1983).

. Antología poética. Luz Méndez (ed.), Guatemala: Editorial ArtemisEdinter, 2000.

Íñiguez Rodríguez, Enrique. "Un modelo de evaluación de la calidad para la traducción de poesía: Cavafis en español", Sendebar. Revista de Traducción e Interpretación. Universidad de Granada 26 (2015): 195-212. 
Jones, Francis R. "Poetry Translation". Handbook of Translation Studies (2011): $117-122$.

Kaminsky, Amy K. After Exile. Writing The Latin American Diaspora. Minneapolis: University of Minnesota Press, 1999.

Koster, Cees. From World to World: An Armamentarium For The Study Of Poetic Discourse In Translation. Amsterdam: Rodopi, 2000.

Lorenzano, Sandra. "Pequeño homenaje a Alaíde Foppa a través de sus poemas", 2010. Consultado 03/12/16. http://sandralorenzano.blogspot.be/2010/12/ pequeno-homenaje-alaide-foppa-traves-de.html.

Ludec, Nathalie. "Alaíde Foppa... una escritora guatemalteca desaparecida... Su nombre a través de la Red”. Debate feminista, Año 11, Vol. 22, octubre 2000.

MacMasters, Merry. "Recopilarán en un libro los escritos de Alaíde Foppa, anuncian en la UNAM". La Jornada 5 de diciembre de 2014. Consultado 27/06/16. http://www.jornada.unam.mx/2014/12/05/cultura/a06n1cul.

Millán, Márgara. "Revistas y políticas de traducción del feminismo mexicano contemporáneo". Estudos Feministas, 17(3): 312, sep/dec. (2009): 819-846.

Monterroso, Augusto. "El avión a Managua", La letra e (Fragmentos de un diario). Madrid: Alfaguara (1998): 154.

Oxford Dictionary of National Biography. Consultado 19/08/15. http://www. oxforddnb.com.

Oxlie of Morpet, Mary. "To William Drummond of Hawthornden". A Book of Women's Verse. Ed. J. C. Squire. Oxford: Clarendon Press. 1921. Consultado 27/06/16. https://archive.org/details/bookofwomensvers00squirich.

Paniagua, Lita. "Carta a Alaíde”. En Foppa, A. Los dedos de mi mano. Selección de poemas del libro. Asociación de Trabajadores de la Cultura de Guatemala "Alaíde Foppa", 1.3 (1983): 22. 
Poniatowska, Elena. "Alaíde Foppa 31 años después”. La Jornada 21 de octubre de 2012. Consultado 27/06/16. http://www.jornada.unam.mx/2012/10/21/ cultura/a03a1cul.

Rossi, Annunziata. "Una semblanza de Alaíde Foppa". Debate feminista, Año 11, Vol. 22, octubre 2000

Salinas, Gilda. Alaíde Foppa. El eco de tu nombre. México: Grijalbo, 2002.

Tcherepashenets, Nataly. "Borges on poetry and translation in theory and practice”. Variaciones Borges 19 (2005): 183-194.

Venuti, Lawrence (ed.). Poetry and Translation. Special issue Translation Studies 4-2, London: Routledge, May 2011.

Recebido em: $12 / 08 / 2017$ Aceito em: 06/10/2017 Publicado em janeiro de 2018

* An Van Hecke es profesora titular de español y coordinadora del Máster de Traducción de la Facultad de Filología de la Universidad Católica de Lovaina (KUL), campus Amberes. Tras sus estudios de Filología Hispánica en la Universidad Católica de Lovaina (1990), obtuvo su título de licenciada en Estudios Latinoamericanos en la UNAM de México (1993) y de doctorado en Filología en la Universidad de Amberes con una tesis del autor guatemalteco Augusto Monterroso (2005). Ha publicado artículos sobre literatura mexicana, chicana y guatemalteca. Su libro Monterroso en sus tierras (2010) fue publicado por la editorial Universidad Veracruzana de México. Sus intereses son la literatura de los siglos XX y XXI, principalmente sobre migración, exilio, identidad (post) nacional, relaciones interculturales e intertextualidad. Su investigación actual se centra, entre otros aspectos, en autotraducción, bilingüismo, y code-switching en literatura chicana. E-mail: An.VanHecke@kuleuven.be 